\title{
MAGNETIC PURIFICATION OF MATING TETRAHYMENA
}

\author{
by \\ PETER J. BRUNS* and KNUD MAX MØLLER \\ Biological Institute, Carlsberg Foundation \\ Tagensvej 16, DK-2200 Copenhagen N \\ * Permanent address: Botany, Genetics and Development \\ Cornell University, Ithaca, New York 14853. U.S.A \\ and \\ VAGN LEICK \\ Biochemical Institute B, University of Copenhagen \\ Panum Institute. Blegdamsvej 3. DK-2200 Copenhagen N
}

Keywords: Tetrahymena, conjugation, ferrite, magnetic separation

The ability to ingest particles is lost during conjugation in the ciliate Tetrahymena. Since ingestion does not resume until the late stages of development (several hours after pair separation), differential particle uptake can be exploited to isolate conjugating cells. A magnetic separation method is presented which should be applicable to many cellular systems. Pure preparations of mating Tetrahymena make possible molecular studies on the development of this organism.

\section{INTRODUCTION}

Lower eukaryotes have been successfully employed to study many aspects of eukaryotic development. Studies on the cell cycle in yeast (8) and development in Dictyostelium, Physarum, and other eukaryotic microorganisms (11) shed important light on how developmental processes are organized and controlled. However, some important aspects of development, such as programs leading to the differentiation of somatic cells from the original totipotent zygote, may not be amenable to study in these organisms, since they use the same nucleus for somatic and germinal functions. The ciliated protozoa offer a

Abbreviations: Tris = tris-(hydroxymethyl) amino methane. 
useful experimental system for these studies since they contain separate germinal and somatic nuclei, but can still be cultured and mated in large numbers.

Sexually competent strains of Tetrahymena thermophila, formerly Tetrahymena pyriformis (10), contain two morphologically distinct nuclei (the germinal micronucleus, and the somatic macronucleus) which contain essentially the same genome (14), but are different in many aspects, including transcriptional activity, time and amount of DNA synthesis, content of histones, and organization of the genes for ribosomal RNA (13). The two different nuclei develop from a common nucleus during conjugation. After pairs have formed, a precise sequence of nuclear events leads to the establishment of a new recombinant germinal nucleus, and then to the development of a new somatic nucleus from the germinal nucleus. The whole process takes about 20 hours at $30^{\circ} \mathrm{C}$, and can be performed with large samples of cells at concentrations of $1-2 \times 10^{5}$ cells $\cdot \mathrm{ml}^{-1}$ (see ref. 6 for conditions necessary for pairs to form). Thus conjugation in Tetrahymena offers many possibilities for molecular studies of nuclear development including meiosis and nuclear differentiation. A necessary prerequisite for such studies is the production of mating mixtures with high frequencies of paired cells. Moreover, it has long been observed that not all pairs complete conjugation. Typically $10 \%$, but sometimes as many as $75 \%$, of isolated pairs do not develop new macronuclei from the newly generated recombinant micronuclei (see, for example, 7). In order to facilitate molecular studies of conjugation, we have developed and present here a method for the selective purification of pairs and exconjugants developing new macronuclei.

\section{RESULTS}

It has previously been observed that Tetrahymena is normally capable of ingesting particles via the oral apparatus into food vacuoles, and that this ability is subject to control; vacuole formation ceases at the time of cell division during normal growth (5). To demonstrate a similar difference in particle uptake between mating and non-mating cells, firm pairs (five hours after the first pairs have formed) were

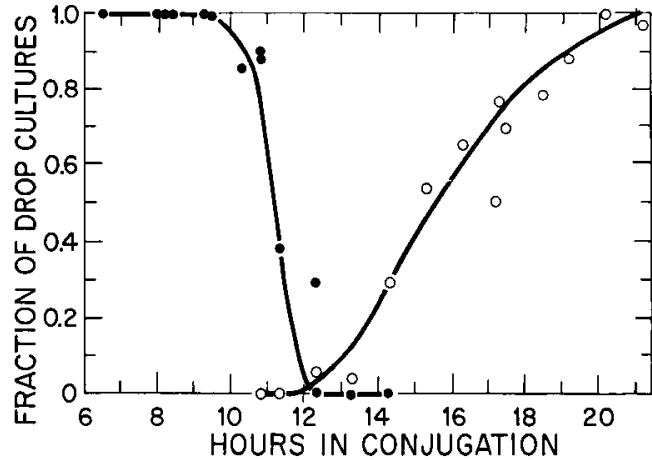

Figure 1. Measurement of pair separation and food vacuole formation kinetics.

Cells of strain B18684 and $\mathrm{Mpr} / \mathrm{Mpr}(6 \mathrm{mps}, \mathrm{V})$ (see 11 for explanation of nomenclature) were grown in PPYS medium: $1 \%$ proteose peptone (Difco) $0.1 \%$ yeast extract (Difco), and $0.003 \%$ Sequestrine (Geigy). They were washed into $10 \mathrm{~mm}$-Tris $\mathrm{HCl}$ buffer, pH 7.4, and starved separately for 12 hours, all at $30^{\circ} \mathrm{C}$. Equal volumes of the two strains were then mixed and, after six hours at $30^{\circ} \mathrm{C}$, a drop of the mating mixture was added to $1 \mathrm{ml}$ of the growth medium. Single pairs were isolated into drops of the growth medium containing $0.1 \%$ India ink (Rotring, W. Germany). The drops were then frequently inspected at 50 and $100 \times$ at $30^{\circ} \mathrm{C}$. At the conclusion of the observations, the plates were kept at $30{ }^{\circ} \mathrm{C}$ for two days and then replicated to microtiter plates containing $0.1 \mathrm{ml}$ PPYS per well. After two days the cultures were replicated to a fresh set of microtiter plates, and after 12 hours at $28^{\circ} \mathrm{C}$, an equal volume of $30 \mu \mathrm{g} \cdot \mathrm{ml}^{-1}$ 6-methylpurine $(6-\mathrm{mp})$ in PPYS was added. Growth or death in the drug was assayed after four days. Only those clones expressing 6-mp resistance had produced new macronuclei during the mating (11): the observations from all other cultures were not included here. - $=$ drops aith pairs: $\mathrm{O}-\mathrm{O}=$ drops with one or more cells containing ink laden food vacuoles.

isolated into small drops of growth medium containing India ink, and observed both for pair separation and ink uptake into food vacuoles. In addition, non-mating cells from the same mating mixtures were isolated into the ink-nutrient broth; ink filled food vacuoles were easily seen in these control cells within 15 minutes, in agreement with previous studies (12). On the other hand, when isolated into ink-growth medium and observed repeatedly soon thereafter, 0 out of 378 pairs formed food vacuoles, and 
non showed vacuole formation until, on the average, five hours after pair separation. Figure 1 shows the frequency with which pairs occur in drop cultures, as well as the frequency of pairs in the cultures containing at least one cell with food vacuoles. Only those cultures which upon subsequent testing proved to have developed new macronuclei have been included. We conclude that both pairs and single cells in the later stages of conjugation do not ingest particles.

In order to isolate pairs and true conjugants on the basis of differential particle uptake, a method to separate particle-filled from particlefree cells was developed, based on the techniques designed for vegetative cell synchrony, using iron particles for ingestion and magnets for separation $(6,9)$. The iron particles used in the previous studies proved to be too large for efficient ingestion by starved cells. Smaller ferrite cubic crystals of $\mathrm{Co}_{0.8} \mathrm{Zn}_{0.2} \mathrm{Fe}_{2} \mathrm{O}_{4}$ with a diagonal dimension of about $20 \mathrm{~nm}$, supplied by the Colloidal Chemical Department of Philips Research Laboratories, Eindhoven, The Netherlands, were readily taken up and concentrated by both growing and starving cells of this strain. We have subsequently found that uncoated 10 $\mathrm{nm}$ magnetic particles which work as well are commercially available from Ferrofluidics, 144 Middlesex Turnpike, Burlington, Mass. 01803. Preincubation of the particles from either source in $1 \%$ aqueous ovalbumin (Sigma A-5503) followed by a 10 -fold dilution by the mating mixture, leaves the particles in suspension. Shaking is thereby avoided, an important condition, since shaking reduced particle ingestion efficiency.

Separation of particle-filled cells has been achieved with small columns of iron-quartz powder, which are fitted with permanent magnets on the outside. The iron powder in the column proved necessary to retard the ferrite containing cells; without the iron in the column, many particle-filled cells passed through the column. To determine a minimum time for ferrite exposure, cells of one mating type were starved in the $10 \mathrm{~mm}$-Tris buffer used for matings $(1,3)$, mixed with ovalbumin-coated ferrite, and passed through the column after various times of incubation in the ferrite; the number of recovered cells was determined by counting. As seen in Figure 2, one hour

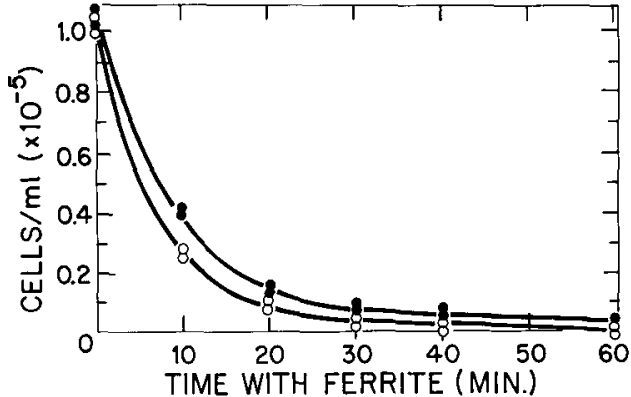

Figure 2. Removal of non-mating Tetrahymena by a magnetic column as a function of time in a ferrite suspension.

Cells of strain B18684 were starved for 12 hours

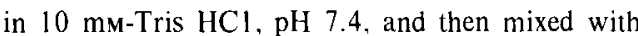
ferrite pretreated with $1 \%$ ovalbumin to give a final concentration of $5(-\infty)$ or $10(0-0)$ $\mathrm{mg} \cdot \mathrm{ml}^{-1}$ ferrite particles in $0.1 \%$ ovalbumin. One $\mathrm{ml}$ of the cell suspension followed by $0.5 \mathrm{ml}$ Tris buffer was passed through a column containing a 1:4 mixture of iron powder (Merck, Darmstadt. no. 3819) to quartz powder (Merck, Darmstadt, no. 7536), layered on top of loosely packed non-wetting cotton. The quartz was washed and dried before use to eliminate finer particles, and packed into Corning disposable Pasteur pipettes. Two $20 \times 50 \times 75 \mathrm{~mm}$ ceramic anisotropic magnets (hard ferrite) from Bakker Magneten, Eindhoven. The Netherlands, with north and south poles on the large surfaces, were clamped on each side of the column with nonmagnetic clamps, and opposite poles facing each other at a distance of about $21 \mathrm{~mm}$. A magnetic field of about 1200 gauss was measured in the center of the column.

incubation with either 5 of $10 \mathrm{mg} \cdot \mathrm{ml}^{-1}$ ferrite was sufficient for removal of all cells. Moreover, using this approach, we found that the maximum capacity of the column was $2 \times 10^{5}$ ferrite laden cells per gram of iron quarts. The rate of flow was found to be optimal with respect to the yield of cells at about $2 \mathrm{ml} \cdot \mathrm{min}^{-1}$.

Finally, we tested the ability of the column to eliminate non-conjugants at the later stages of conjugation by using a mating mixture of cells containing dominant mutations in the micronucleus but recessive markers in the macronucleus, allowing a simple test for the development of new macronuclei (2). Six hours after mixing the two strains, ovalbumin treated ferrite (10 $\mathrm{mg} \cdot \mathrm{ml}^{-1}$ ) was added to the mating mixture, and 
Table I.

Mating behavior of cells recovered from magnetic column. Strains, methods of mating, and assay for conjugants (pairs which had completed conjugation) were the same as for Figure 1.

\begin{tabular}{ccc}
$\begin{array}{c}\text { Hours in conjugation } \\
\text { when sampled }\end{array}$ & $\begin{array}{c}\text { \% Cells in pairs } \\
\text { in column eluate }\end{array}$ & $\begin{array}{c}\text { Frequency of isolates which } \\
\text { developed new macronuclei }\end{array}$ \\
\hline 7 & 99.5 & $144 / 157=.92$ \\
8 & 98.9 & $73 / 76=.96$ \\
10 & 89 & $74 / 78=.96$ \\
12 & 27 & $77 / 78=.99$ \\
14 & 3 & $67 / 67=.100$ \\
\hline
\end{tabular}

samples were run through the column at various times. At each time point, a portion of the column eluate was fixed with an equal volume of $4 \%$ formaldehyde to determine percent cells in pairs. Random cells in the eluate (no distinction was made between paired or unpaired) were cloned in drops of nutrient broth. The clones were grown and tested for the expression of the dominant phenotype to identify those which had developed a new macronucleus. Table I shows that although the column initially yielded nearly $100 \%$ cells in pairs, the frequency of paired cells in the column eluate dropped with time exactly as predicted by Figure 1 (pair dissociation occurs before the onset of particle ingestion). Moreover, recovery of cells which developed a new macronucleus reached $100 \%$ in the 14 hour sample. Presumably only exconjugants synthesizing new macronuclei had delayed the resumption of particle ingestion at this time. A Feulgen stain of the cells recovered at 14 hours confirmed that virtually every cell was developing macronuclear anlagen. Only 2 out of 700 cells had the nuclear appearance of cells not undergoing the nuclear development characteristic of this stage.

Thus we conclude that the specific relationship between changes in the capacity to ingest particles, and the nuclear events in conjugation makes possible an efficient isolation, both of pairs during early conjugation and of cells synthesizing new somatic nuclei during the later stages of this developmental sequence.

\section{ACKNOWLEDGEMENTS}

We are deeply indebted to the late Professor ERIK ZeutheN, who died on the 10th of January
1980 , for his always enthusiastic support and for everything he put at our (P.J.B.) disposal.

We wish to thank Dr. Ir. A. A. VAN DER GIESSEN and Dr. G. Frens of the Philips Research Laboratories, N. V. Philips Gloilampenfabrieken Eindhoven, The Netherlands, for generous gifts of ferrite material.

We also thank Diana Bruns for assistance, and MARC OrbaCH for unpublished results. This work was supported by NSF Grant PCM77. 07056 to Peter J. Bruns. P.J.B was a John Simon Guggenheim Fellow.

\section{REFERENCES}

1. Bruns, P. J. \& T. B. Brussard: Positive selection for mating with functional heterokaryons in Tetrahymena pyriformis. Genetics 78, 831-841 (1974)

2. Bruns, P. J. \& T. B. Brussard: Pair formation in tetrahymena pyriformis, an inducible developmental system. J. Exptl. Zool. 188, 337-344 (1974)

3. Bruns, P. J. \& R. F. Pai.estine: Costimulation in Tetrahymena pyriformis: A developmental interaction between specially prepared cells. Develop. Biol. 42, 75-83 (1975)

4. Byrne, B. C., T. B. Brussard \& P. J. Bruns: Induced resistance to 6-methylpurine and cycloheximide in Tetrahymena pyriformis. I. Germ line mutants. Genetics 89, 695-702 (1978)

5. Chapman-Andresen, C. \& J. R. Nilsson: On the vacuole formation in Tetrahymena pyriformis, GL. Compt. Rend. Trav. Lab. Carlsberg 36, 405-432 (1968)

6. Dickinson, J. R., M. G. Graves \& B. E. P. Sworoda: Cyclic AMP metabolism in the cell cycle of Tetrahymena pyriformis. FEBS Letters $65,152-154$ (1976) 
7. Gorovsky, M. A.: Macro- and micronuclei of Tetrahymena pyriformis: A model system for studying the structure and function of eukaryotic nuclei. J. Protozool. 20, 19-25 (1973)

8. Hartwell, L. H., J. Culotti, J. R. Pringle \& B. J. ReID: Genetic control of the cell division cycle in yeast. Science 183, 46-51 (1974)

9. Hildebrandt, A. \& F. Duspiva: Ein einfache Methode zur Synchronisation grösserer Pupulationen des Ciliaten Tetrahymena pyriformis (EHRENBERG). Z. Naturforsch. 24b. 747-750 (1969)

10. Nanney, D. L. \& J. W. MCCoy: Characterization of the species of the Tetrahymena pyriformis complex. Trans. Amer. Microsa Soc. 95. 664682 (1976)
11. O'Day, D. \& P. Horgen (eds.): Eukaryotic microbes as model developemental systems. Dekker, New York (1977)

12. Rasmussen, L.: Nutrient uptake in Tetrahymena pyriformis. Carlsberg Res. Commun. 41, 143$167(1976)$

13. YaO, M. C. \& J. G. Gall: A single integrated gene for ribosomal RNA in a eucaryote, Tetrahymena pyriformis. Cell 12, 121-132 (1977)

14. YAO, M. C. \& M. A. Gorovsky: Comparison of the sequences of macro- and micronuclear DNA of Tetrahymena pyriformis. Chromosoma 48. 118 (1974) 